\title{
Triple Discordances in Receptor Status During Breast Cancer Local Progression and Metastases: Case Report and Literature Review
}

This article was published in the following Dove Press journal: OncoTargets and Therapy

\section{Adrian Martuszewski (D) Patrycja Paluszkiewicz (D) ${ }^{\prime}$ Mateusz Nowak (iD) Krzysztof Szewczyk iD ${ }^{2,3}$ Urszula Staszek-Szewczyk (iD) ${ }^{2,4}$ \\ 'Wroclaw Medical University, Wroclaw, Poland; ${ }^{2}$ Wroclaw Medical University, Department of Oncology, Division of Surgical Oncology, Wroclaw, Poland; ${ }^{3}$ Wroclaw Regional Comprehensive Cancer Center, Ist Department of Surgical Oncology, Wroclaw, Poland; ${ }^{4}$ Wroclaw Regional Comprehensive Cancer Center Department of Brachytherapy, Wroclaw, Poland}

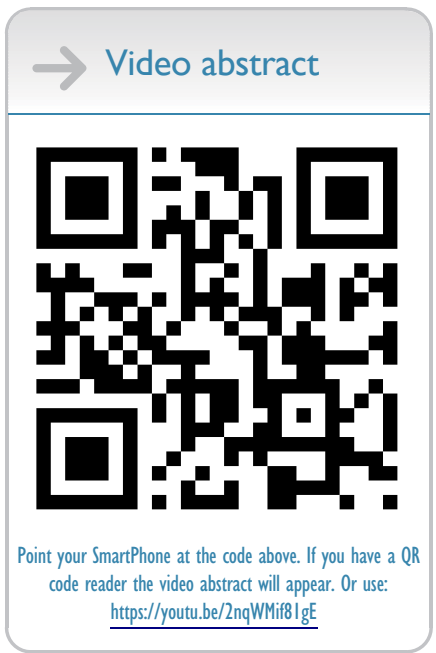

Correspondence: Urszula StaszekSzewczyk

Wroclaw Regional Comprehensive Cancer Center, PI. Hirszfelda I2, Wroclaw 53-4I2,

Poland

$\mathrm{Tel}+48508 I 16999$

Fax +48 7136191II

Email urszula.staszek-szewczyk@umed. wroc.pl

\begin{abstract}
Breast cancer is the most common female malignant neoplasm in Poland and around the world. Precise determination of tumor molecular profile allows application of appropriate anticancer therapy, increasing the chances of recovery. A 28-year-old woman detected a thickening in her left breast. Mammography showed a change measuring $60 \mathrm{~mm}$ (radiologically BIRADS 5). The biopsy revealed invasive ductal carcinoma, luminal subtype B, HER2 positive (cT3N1M0). Neoadjuvant chemotherapy was administered and then breast conserving surgery was performed. In postoperative histopathology cancer, biological subtype was evaluated: HER2 positive, nonluminal (ypT2ypN0cM0). Then, postoperative radiotherapy was performed. After 14 months, breast ultrasonography (US) and mammography (MGF) revealed the presence of suspicious changes (BIRADS 4). Tru-cut biopsy confirmed cancer recurrence (luminal subtype B, HER2 negative, ER negative, PgR: 10\%, Ki-67: 70\%). Despite implemented and modified chemotherapy regimens, local progression occurred. Genetic testing excluded $B R C A$ gene mutation. The patient qualified for radical mastectomy modo Halsted (ypT4bN0cM0). Postoperative microscopic examination revealed triple negative breast invasive carcinoma of no special type. After 22 months, metastatic lesions in lungs and left retrosternal nodes appeared. Due to the limited possibilities of systemic treatment, the patient qualified for stereotactic radiotherapy of tumors in the lungs' and left retrosternal nodes. Advancement, histological type and molecular profile should be controlled at each stage of the disease, as they may change several times and require modification of therapy.
\end{abstract}

Keywords: biological subtype, phase disease, personalized treatment

\section{Introduction}

In Poland, cancer is the second cause of death following cardiovascular diseases and within the next 10 years in might take first place. ${ }^{1}$ In 2017 breast cancer accounted for $22 \%$ of all malignant neoplasms in woman and was the second most common cancer-related death $(14,8 \%)^{2}$

Disease frequency yielded for screening tests to reduce mortality. Worldwide mammography (MGF) is the most commonly used, most widely researched and recommended early detection tool for women aged between 40 and 74, being most effective after 50 years of age. Ultrasound and magnetic resonance imaging are complementary diagnostic methods. For women with a positive family history of 
breast/ovarian cancer, not necessarily with $B R C A$ mutation, breast self-examination is among the recommended tests. $^{3,4}$

Breast cancer treatment is implemented only after confirming the diagnosis with microscopic tissue sample examination. Core needle biopsy of suspected region is the recommended procedure. Excisional and incisional biopsy, fine needle aspiration (FNA) of the breast tumor and FNA of suspicious axillary lymph nodes are among other possible interventions. Pathology report should always contain histopathologic breast cancer type, estrogen (ER) and progesterone receptor status (PgR), human epidermal growth factor receptor 2 (HER2) overexpression confirmation and Ki-67 proliferation index. ${ }^{4}$

Nowadays, breast cancer treatment is based on multidisciplinary and personalized approach to each case. It includes surgery, radiotherapy, and systemic treatment. Researchers have shown such an approach significantly increases the chances of therapeutic success and reduces mortality compared with lack of multidisciplinary treatment. ${ }^{5}$

Breast conserving surgery (BCS) with sentinel lymph node biopsy (SLNB) or axillary lymphadenectomy (LAD), mastectomy with SLNB or LAD is performed depending on the level of locoregional advancement. Radiotherapy (RT) is mandatory after BCS and after mastectomy in cases with tumors larger than $5 \mathrm{~cm}$ and/or numerous lymph node metastases $(\geq 4)$ and it should also be considered in patients with one to three positive axillary lymph nodes. In cases with positive steroid receptor expression (ER+ and/or $\mathrm{PgR}+$ ) hormone therapy is administered. Chemotherapy can be applied pre- or postoperatively, depending on individual indications. In systemic breast cancer treatment patients with HER 2 overexpression receive targeted therapy with monoclonal antibody trastuzumab. ${ }^{4}$

According to the 4th European School of Oncology (ESO)_ European Society for Medical Oncology (ESMO) International Consensus Guidelines for Advanced Breast Cancer (ABC 4) in previously irradiated patients, re-irradiation of the whole or part of the chest wall may be considered in selected cases. ESMO guidelines for recurrent and metastatic breast cancer recommend stereotactic radiosurgery for single brain metastases as an alternative to surgical treatment. High rates of local control, which can potentially lead to survival benefits, justify considering stereotactic radiotherapy in patients with limited pulmonary oligometastases. ${ }^{6,7}$
The introduced case is worth reading because of dynamic changes in the biological profile of the tumor, which might have been influenced by treatment or dependent on the heterogeneity of the tumor. At the same time, it shows a multidisciplinary approach to cancer therapy, which requires cooperation between the patient and physicians of many specialties. ${ }^{5}$

\section{Case Report}

A 28-year-old Caucasian woman, with positive family history, reported to the physician because of left breast tumor, which she sensed during breast self-examination (BSE).

MGF and ultrasonography (US) showed focal lesion with blurred outlines in the upper external quadrant of the left breast, measuring $60 \mathrm{~mm}$ and pathological lymph nodes in left axillary region measuring $18 \mathrm{~mm}$ (radiologically, BIRADS 5). Core needle biopsy revealed invasive cancer of no specific type (NOS) with positive estrogen receptors $(\mathrm{ER}+++)$, progesterone receptors $(\mathrm{PgR}+++)$, HER2 amplification and Ki-67 proliferation index at the level of $98 \%$ (luminal subtype B, HER2+) (cT3N1M0). Neoadjuvant chemotherapy was implemented. The patient received four AC courses (doxorubicin/cyclophosphamide) and three docetaxel courses. US examination performed after the third course of chemotherapy showed response to treatment, tumor dimensions were $38 \times 31 \mathrm{~mm}$, with $75 \%$ fluid component, without pathological lymph nodes in the left axilla. Breast conserving surgery with left axillary lymphadenectomy was performed six months after the diagnosis.

Postoperative histopathology revealed biological subtype change from luminal B, HER2+ to nonluminal, HER2 + (Ki-67 80\%, ER-, PgR-) (ypT2ypN0cM0). Patient received complementary RT for left breast and regional lymph nodes drainage with left internal mammary nodes volume to total dose (TD) 50.4 Gy in 28 fractions with additional dose to tumor bed to TD 60.2 Gy in 28 fractions. RT was followed by 13 trastuzumab courses with three paclitaxel infusions. Nine months after BCS, the left breast US and MMG examination showed the presence of mild changes (BIRADS 2), and after another six months there was a suspicious change, measuring $43 \mathrm{~mm}$ (BIRADS 4) in treated breast.

Tru-cut biopsy (TCB) was performed and confirmed presence of recurrent luminal $\mathrm{B}$ breast cancer (ER-, $\mathrm{PgR}+$ ) without HER2 amplification, Ki-67-70\%. Chemotherapy was administered and included five paclitaxel, two 
capecitabine+vinorelbine, two cisplatin alone, eight cisplatin+gemcitabine, two doxorubicin+cyclophosphamide infusions. Despite several drug changes, the relapse was significantly progressive (Figure 1). During therapy genetic tests were carried out and excluded $B R C A 1$ and $B R C A 2$ mutations. After surgical consultation the patient qualified for modified extended left-sided mastectomy (Halsted's method) - the breast gland was removed along with partially infiltrated pectoralis muscle. Postoperative microscopic examination revealed breast invasive cancer NOS, triple negative (ypT4bpNxcM0, R0 resection).

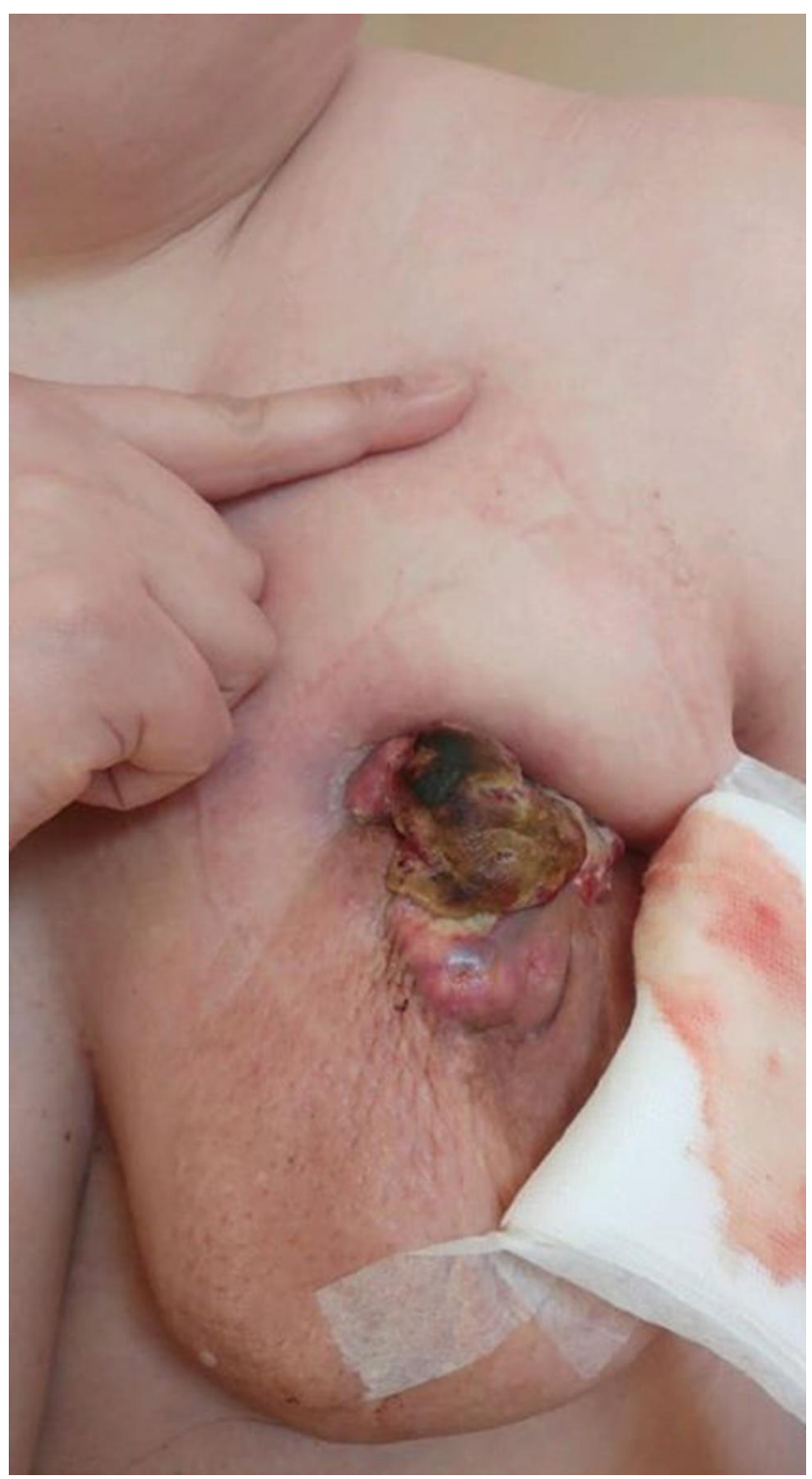

Figure I Recurrence of local breast cancer, luminal subtype B, HER2 negative. In the scar after the procedure, a visible malignant lesion not responding to chemotherapy of $59 \times 29 \mathrm{~mm}$ in size and infiltrating the skin surface.
Twenty-two months after Halsted's mastectomy, three lesions were found on imaging studies. Radiologically they suggested metastatic changes: pathological left retrosternal nodes $(42 \times 25 \mathrm{~mm})$, right lung nodule at the border of segments 2 and $3(10 \times 7 \mathrm{~mm})$ and left lung nodule at the border of segments 1 and 2, of similar size. Abdominal and pelvis computed tomography (CT) did not show any oncologically significant changes. Due to the lack of systemic treatment options (no response to previous multiagent chemotherapy and local recurrence progression two years earlier), the patient qualified for nonpalliative stereotactic body radiotherapy (SBRT) for right and left lung tumor and left retrosternal lymph nodes.

Respiratory gating SBRT, with $6 \mathrm{MeV}$ photon beam, for the right lung tumor volume to total dose of $50 \mathrm{~Gy}$ in five fractions for $80 \%$ isodose and for the left lung tumor volume and retrosternal nodes tumor volume to TD of 30 Gy in five fractions for $80 \%$ isodose was performed (Figures 2 and 3). Thirty Grays total dose to left lung and retrosternal region was administered after analyzing radiotherapy plan executed post BCS. Previously absorbed dose by retrosternal nodes tumor volume and organs at risk (lungs, heart, ribs, sternum) dictated re-irradiation schema for the patient's safety.

Control CT performed three months post RT showed significant regression of metastatic changes: pathological left retrosternal nodes $(25 \times 18 \mathrm{~mm})$, right lung nodule at the border of segments 2 and $3(7 \times 4 \mathrm{~mm})$ and left lung nodule at the border of segments 1 and 2 (from 9x7 mm to $7 \times 3 \mathrm{~mm}$ ) (Figures 4 and 5). The study also revealed soft tissue infiltration of $35 \times 20 \mathrm{~mm}$ next to ascending aorta and pulmonary trunk, extending along the posterior surface of the sternum shaft. Positron emission tomography (PETCT) carried out after one month revealed banded fibrous changes located retrosternally without pathological glucose intake. No structural and metabolic focal lesions throughout the whole body were revealed. Subsequent CT (eight months post SBRT) confirmed complete pathological response.

\section{Discussion}

Accurate evaluation of ER, PgR and HER2 amplification in histopathological examination is the starting point to determine the appropriate biological subtype of tumor and thus to select the most effective therapy. ${ }^{8}$ Incompatibilities in histopathological evaluation may be influenced by different factors, such as: investigator's level of experience, sampling protocols, tissue fixation, storage and other technical artifacts. 


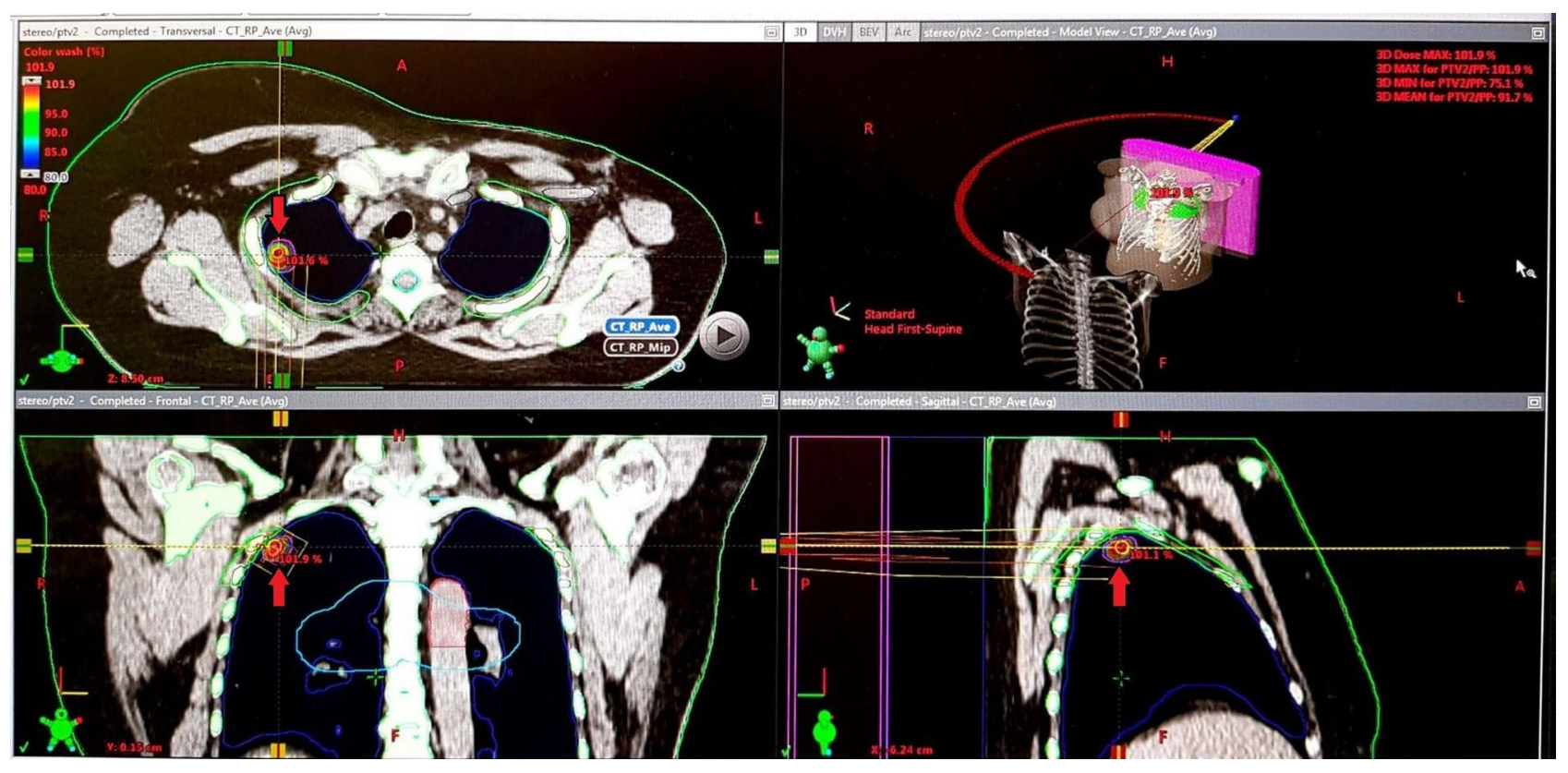

Figure $2 \mathrm{~A}$ picture from the planning system. Visible right lung tumor at the border of segments 2 and $3(7 \times 4 \mathrm{~mm})$.

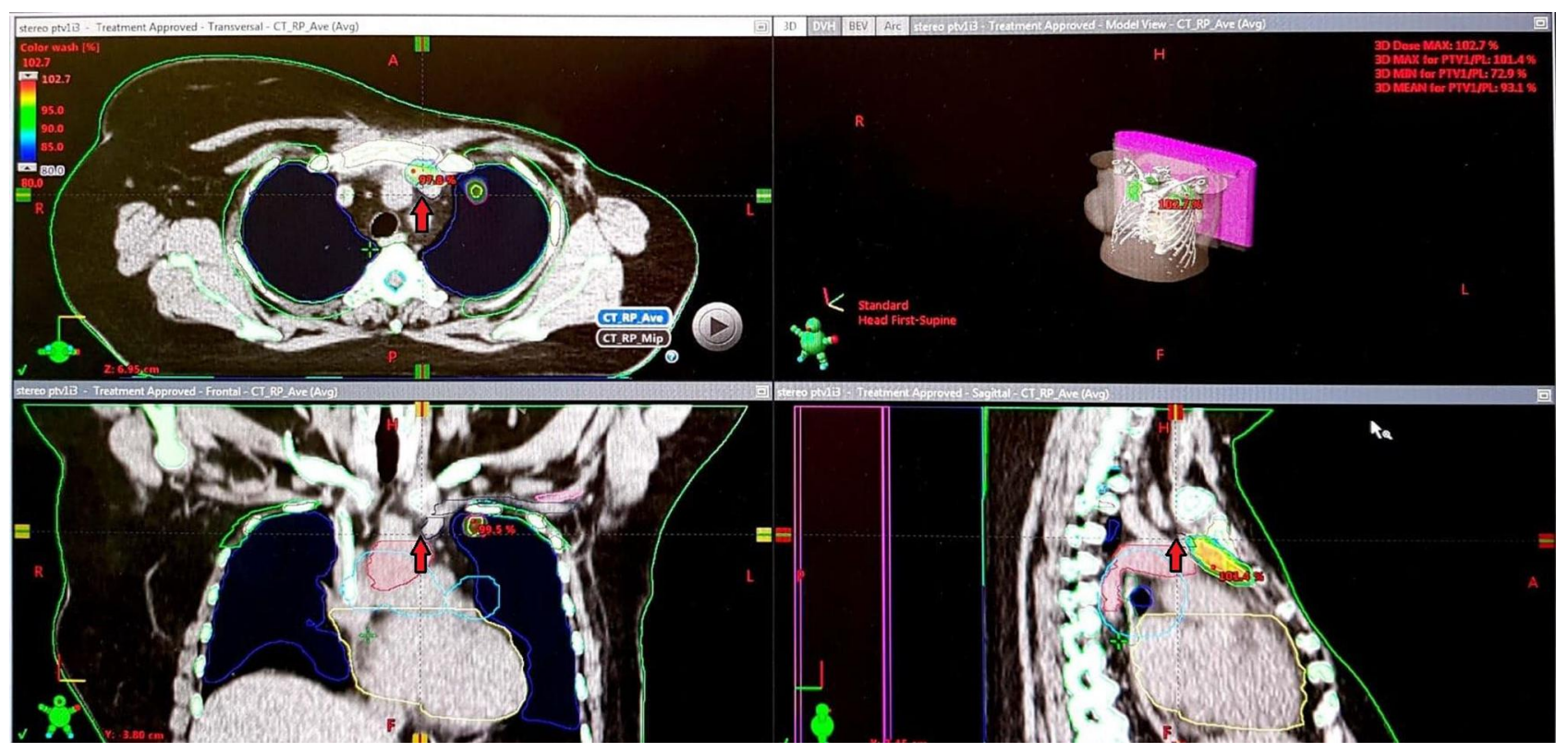

Figure $3 \mathrm{~A}$ picture from the planning system. Visible left lung tumor at the border of segments 1 and 2 (from $9 \times 7 \mathrm{~mm}$ to $7 \times 3 \mathrm{~mm}$ ) and retrosternal lymph nodes $(25 \times 18 \mathrm{~mm})$.

Allott et al, studying the effect of spatial heterogeneity of receptor expression on breast cancer classification, confirmed that differences in ER, PgR, and HER2 evaluation occurred in $9 \%, 16 \%$, and $18 \%$ of cases, respectively. Such heterogeneity may have contributed to misclassification of biological subtype and could have had serious therapeutic implications. ${ }^{9-11}$

During the progression of cancer, relapse or spread, its molecular phenotype may change. Guarneri et al analyzed
75 cases of primary breast cancer tumors and paired metastases. It was stated in the discussion that several factors could contribute to discrepancies in receptor and HER2 status, such as genetic drift during tumor progression, intratumoral heterogeneity, and selective pressure of therapies. ${ }^{12}$ Similarly a study published by Dieci et al showed that the loss of receptor expression in breast cancer during relapse worsened patients' prognosis. The 


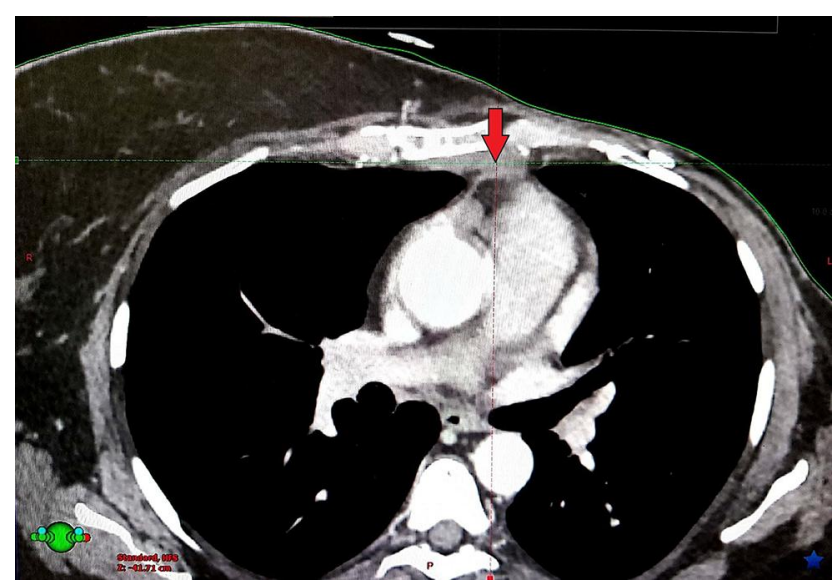

Figure 4 Suspected tumor progression marked by red arrow- transverse view.

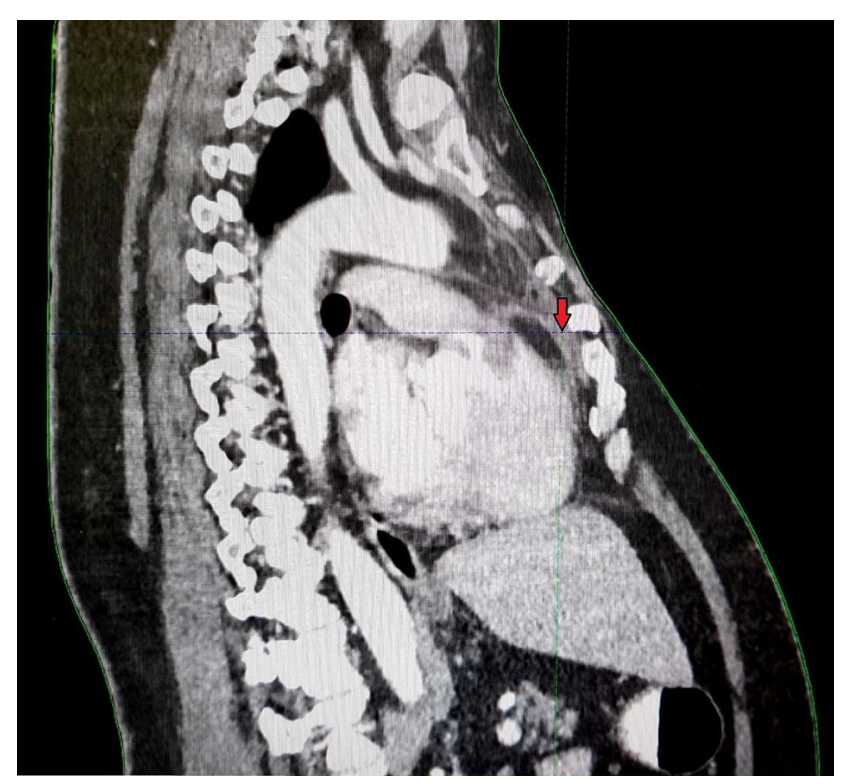

Figure $\mathbf{5}$ Suspected tumor progression marked by red arrow- lateral view.

authors analyzed 119 cases of locoregional recurrences and distant breast cancer, of which 27 patients had discordance of receptor expression. It was concluded that selection of resistant clones formed as a result of chemotherapy and biological switching led to more aggressive phenotype. Loss of ER, PgR and HER2 resulted in worse prognosis than in the case of positive receptors and HER2 amplification, which was confirmed in this case. ${ }^{13,14}$ Curtit et al demonstrated that chemotherapy, especially anthracycline based, may induce change in ER and PgR receptor expression. ${ }^{15}$ It is very important to constantly monitor the biological subtype of each relapse or spread of breast cancer. It allows implementation of the most effective treatment possible or to stop ineffective and potentially serious adverse reactions. According to Voduc et al and Arvold et al breast cancer relapse rates also vary statistically significantly depending on biological subtype. Increased risk of local recurrence was observed in patients with luminal B, luminal HER2 positive and triple negative cancer. $^{16,17}$

Oligometastatic disease, defined as small number of metastatic lesions (according to most definitions $\leq 5$ ), in a limited number of organs, currently qualifies as an intermediate prognosis. It is a treatable condition provided that effective therapy is used. ${ }^{18}$ In 1995 Hellman and Weichselbaumput forward the hypothesis that oligometastasis local control (LC) could improve prognosis. ${ }^{19,24}$ One of the most prevalent distant metastatic sites in breast cancer are the lungs, where local treatment in combination with systemic therapy plays important role. In oligometastatic patients, surgical treatment has given similar results in LC and survival to SBRT, with SBRT having a good toxicity profile. ${ }^{18,20}$

Metastatic breast cancer treatment is mainly based on systemic therapy, but recently, metastasis-directed therapy, especially in oligometastatic disease, has become increasingly important. Oligometastatic breast cancer (OMBC) can be treated with ablative radiotherapy. SBRT applied in described case had acceptable safety profile and satisfactory local effectiveness. Compared to fractionated intensity-modulated radiation therapy (IMRT), SBRT has better treatment results. ${ }^{21}$ In one multicenter prospective study involving OMBC patients with metastatic sites including lymph nodes and lungs, better progression-free survival (PFS) and overall survival (OS) was observed. Advantage of stereotactic RT is an effective and noninvasive treatment of metastases located inside and outside the brain. Precise imaging of metastatic lesions and the possibility of achieving a high dose focused in the metastatic lesion, while sparing neighboring organs at risk, enabled effective hypofractionated radiotherapy treatment. SBRT proved to be minimally invasive, safe and extremely effective. However, the limitation is that the data were retrospective and study groups small, which might have given inaccurate results. ${ }^{21,22}$

SBRT with dose per fraction $>10$ Gy causes damage to double stranded DNA in tumor cells and vascular dysfunction of the tumor. After SBRT the inflammatory reaction leads to increase of immune system cells. Interferons, interleukins, colony stimulating factors, tumor necrosis factor alpha and beta tumor growth factor can be variously expressed in place of radio ablation. ${ }^{21}$ 
Hypofractionated regimen causes other biological effects than fractionated RT. SBRT, similarly as fractionated radiation kills tumor cells directly in the area of high doses, it additionally induces vascular effects, which contribute to tumor control. Studies have shown that high-dose radiotherapy causes endothelial apoptosis via sphingomyelin. This means that cancer cells after such radiotherapy have lowered death threshold and are deprived of nutrients by antiangiogenic effect of the therapy. ${ }^{23}$ In addition, SBRT has also shown immune system activation that leads to increased production of gamma interferon and increased the response of CD8 T lymphocytes. CD8 T lymphocyte response worked as an additive to radiotherapy effect and resulted in primary tumor reduction and had an abscopal effect on distant metastases. Such anticancer effects were not observed in conventional fractional radiotherapy or chemotherapy. ${ }^{24}$

\section{Conclusions}

The described case confirms that there is a possibility of multiple changes in breast cancer biological subtypes. As described in the literature from primary, through post neoadjuvant tumor to local relapse. Therefore, it is necessary to control the molecular subtype at every disease stage, and to modify the treatment when necessary.

The key tests to determine breast cancer subtypes are histopathological, immunohistochemical and molecular examinations. Their results determine the method of treatment. Thus they should be performed with the greatest possible precision, care, and repeatability.

Loss of steroid receptor expression and HER2 overexpression in case of relapse results in much worse response or lack of response to systemic therapy and, consequently, worse prognosis. Therefore alternative treatment methods should be considered, taking to account the patients safety and will to continue treatment.

All specialists contributing to multimodal breast cancer treatment should endeavor to communicate efficiently to identify the change in the patient's tumor status in order to choose the most suitable therapy option. In cases with numerous recurrences and/or distant relapse careful treatment selection, with alternative methods, such as extensive surgery, reirradiation or SBRT should be weighed. It must be remembered for the patients' safety that attentive choice of therapy is crucial due to previous treatments and their side effects.

\section{Abbreviations}

MGF, mammography; FNA, fine needle aspiration; ER, estrogen; PgR, progesterone receptor; HER2, human epidermal growth factor receptor 2; BCS, breast conserving surgery; SLNB, sentinel lymph node biopsy; LAD, axillary lymphadenectomy; RT, radiotherapy; ESO, European School of Oncology; ESMO, European Society for Medical Oncology; $\mathrm{ABC}$, advanced breast cancer; BSE, breast self-examination; US, ultrasonography; NOS, cancer of no specific type; TD, total dose; TCB, tru-cut biopsy; CT, computed tomography; SBRT, stereotactic body radiotherapy; PET-CT, positron emission tomography; LC, local control; OMBC, oligometastatic breast cancer; IMRT, intensity-modulated radiation therapy; PFS, progression-free survival; OS, overall survival.

\section{Ethics Statements}

Formal institutional review board (IRB) approval for this study was not required.

Written informed consent was provided by the patient to have the case details and any accompanying images published.

\section{Acknowledgments}

This study was supported by the Minister of Science and Higher Education of Poland and performed as part of the subject registered in the Simple system at number SUB. C280.19.050.

\section{Author Contributions}

All authors made a significant contribution to the work reported, whether that is in the conception, study design, execution, acquisition of data, analysis and interpretation, or in all these areas; took part in drafting, revising or critically reviewing the article; gave final approval of the version to be published; have agreed on the journal to which the article has been submitted; and agree to be accountable for all aspects of the work.

\section{Disclosure}

The authors report no conflicts of interest in this work.

\section{References}

1. Osowiecka K, Rucinska M, Nowakowski J, Nawrocki S. How long are cancer patients waiting for oncological therapy in Poland? IJERPH. 2018;15(4):577. doi:10.3390/ijerph15040577

2. Wojciechowska U, Didkowska J Zachorowania i zgony na nowotwory złośliwe w Polsce. Krajowy Rejestr Nowotworów, Narodowy Instytut Onkologii im. Marii Skłodowskiej-Curie - państwowy Instytut Badawczy. Available from: http://onkologia.org.pl/raporty/. Accessed May 6, 2020

3. Paluch-Shimon S, Cardoso F, Sessa C, et al. Prevention and screening in BRCA mutation carriers and other breast/ovarian hereditary cancer syndromes: ESMO clinical practice guidelines for cancer prevention and screening. Ann Oncol. 2016;27:v103-v110. doi:10.1093/annonc/ mdw327 
4. Cardoso F, Kyriakides S, Ohno S, et al. Early breast cancer: ESMO clinical practice guidelines for diagnosis, treatment and follow-up. Ann Oncol. 2019;30(8):1194-1220. doi:10.1093/annonc/mdz173

5. Kesson EM, Allardice GM, George WD, Burns HJG, Morrison DS. Effects of multidisciplinary team working on breast cancer survival: retrospective, comparative, interventional cohort study of 13722 women. BMJ. 2012;344(apr26 1):e2718. doi:10.1136/bmj.e2718

6. Cardoso F, Senkus E, Costa A, et al. 4th ESO-ESMO International Consensus Guidelines for Advanced Breast Cancer (ABC 4). Ann Oncol. 2018;29(8):1634-1657. doi:10.1093/annonc/mdy192

7. Siva S, MacManus M, Ball D. Stereotactic radiotherapy for pulmonary oligometastases: a systematic review. J Thoracic Oncol. 2010;5 (7):1091-1099. doi:10.1097/JTO.0b013e3181de7143

8. Orlando L, Viale G, Bria E, et al. Discordance in pathology report after central pathology review: implications for breast cancer adjuvant treatment. Breast. 2016;30:151-155. doi:10.1016/j.breast.2016.09.015

9. Potts SJ, Krueger JS, Landis ND, et al. Evaluating tumor heterogeneity in immunohistochemistry-stained breast cancer tissue. Lab Invest. 2012;92(9):1342-1357. doi:10.1038/labinvest.2012.91

10. Allott EH, Geradts J, Sun X, et al. Intratumoral heterogeneity as a source of discordance in breast cancer biomarker classification. Breast Cancer Res. 2016;18(1):68. doi:10.1186/s13058-016-0725-1

11. McCullough AE, Dell'Orto P, Reinholz MM, et al. Central pathology laboratory review of HER2 and ER in early breast cancer: an ALTTO trial [BIG 2-06/NCCTG N063D (Alliance)] ring study. Breast Cancer Res Treat. 2014;143(3):485-492. doi:10.1007/s10549-013-2827-0

12. Guarneri V, Giovannelli S, Ficarra G, et al. Comparison of HER-2 and hormone receptor expression in primary breast cancers and asynchronous paired metastases: impact on patient management. Oncologist. 2008;13(8):838-844. doi:10.1634/theoncologist.2008-0048

13. Liedtke C, Broglio K, Moulder S, et al. Prognostic impact of discordance between triple-receptor measurements in primary and recurrent breast cancer. Ann Oncol. 2009;20(12):1953-1958. doi:10.1093/ annonc/mdp263

14. Dieci MV, Barbieri E, Piacentini F, et al. Discordance in receptor status between primary and recurrent breast cancer has a prognostic impact: a single-Institution analysis. Ann Oncol. 2013;24 (1):101-108. doi:10.1093/annonc/mds248
15. Curtit E, Nerich V, Mansi L, et al. Discordances in estrogen receptor status, progesterone receptor status, and HER2 status between primary breast cancer and metastasis. Oncologist. 2013;18(6):667-674. doi:10.1634/theoncologist.2012-0350

16. Voduc KD, Cheang MCU, Tyldesley S, Gelmon K, Nielsen TO, Kennecke H. Breast cancer subtypes and the risk of local and regional relapse. JCO. 2010;28(10):1684-1691. doi:10.1200/JCO.2009.24.9284

17. Arvold ND, Taghian AG, Niemierko A, et al. Age, breast cancer subtype approximation, and local recurrence after breast-conserving therapy. JCO. 2011;29(29):3885-3891. doi:10.1200/JCO.2011.36.1105

18. Osti MF, Carnevale A, Valeriani M, et al. Clinical outcomes of single dose stereotactic radiotherapy for lung metastases. Clin Lung Cancer. 2013;14(6):699-703. doi:10.1016/j.cllc.2013.06.006

19. Hellman S, Weichselbaum R.R. Oligometastases. J Clin Oncol. 1995;13(1):8-10 1 doi:10.1200/JCO.1995.13.1.8

20. Milano MT, Katz AW, Zhang H, Okunieff P. Oligometastases treated with stereotactic body radiotherapy: long-term follow-up of prospective study. Int J Radiat Oncol Biol Phys. 2012;83(3):878-886. doi:10.1016/j.ijrobp.2011.08.036

21. Possanzini M, Greco C. Stereotactic radiotherapy in metastatic breast cancer. Breast. 2018;41:57-66. doi:10.1016/j.breast.2018. 06.011

22. Trovo M, Furlan C, Polesel J, et al. Radical radiation therapy for oligometastatic breast cancer: results of a prospective Phase II trial. Radiother Oncol. 2018;126(1):177-180. doi:10.1016/j.radonc.2017.08.032

23. Corbin KS, Hellman S, Weichselbaum RR. Extracranial oligometastases: a subset of metastases curable with stereotactic radiotherapy. JCO. 2013;31(11):1384-1390. doi:10.1200/JCO.2012.45.9651

24. Lee Y, Auh SL, Wang Y, et al. Therapeutic effects of ablative radiation on local tumor require $\mathrm{CD} 8+\mathrm{T}$ cells: changing strategies for cancer treatment. Blood. 2009;114(3):589-595. doi:10.1182/ blood-2009-02-206870
OncoTargets and Therapy

\section{Publish your work in this journal}

OncoTargets and Therapy is an international, peer-reviewed, open access journal focusing on the pathological basis of all cancers, potential targets for therapy and treatment protocols employed to improve the management of cancer patients. The journal also focuses on the impact of management programs and new therapeutic
Dovepress

agents and protocols on patient perspectives such as quality of life, adherence and satisfaction. The manuscript management system is completely online and includes a very quick and fair peer-review system, which is all easy to use. Visit http://www.dovepress.com/ testimonials.php to read real quotes from published authors. 